\title{
1 Identification of small regulatory RNAs involved in persister
}

\section{2 formation}

3 Shanshan Zhang ${ }^{1}$, Shuang Liu ${ }^{1}$, Nan Wu ${ }^{1}$, Wenhong Zhang ${ }^{1 *}$ and Ying Zhang ${ }^{2 *}$

4

${ }^{1}$ Key Lab of Molecular Virology, Institute of Medical Microbiology, Department of Infectious Diseases, Huashan Hospital, Fudan University, Shanghai, China,

${ }^{2}$ Key Lab of Molecular Virology, Institute of Medical Microbiology, Department of Infectious Diseases, Huashan Hospital, Fudan University, Shanghai, China; Department of Molecular Microbiology and Immunology, Bloomberg School of Public Health, Johns Hopkins University, Baltimore, MD, USA

*Correspondence: WH Zhang, E-mail: zhangwenhong@ fudan.edu.cn; Y Zhang, E-mail: yzhang@jhsph.edu

\section{Abstract}

Small regulatory RNA (srRNA) is widely distributed in three kingdoms of life and fulfills functions in many aspects of cellular life, but their role in bacterial persistence remains unknown. In this study, we comprehensively interrogated the expression levels of the known srRNAs on three critical time points, stage 1 (S1) where no persisters are formed, stage 2 (S2) where persisters are beginning to appear, and stage 3 (S3) where persister numbers increase significantly. Three upregulated srRNAs (OmrB, an outer member associated srRNA; RdlB, a swarming motility and curli expression regulator; McaS, a flagellar motility and biofilm formation regulator) overlapping in S2/S1and S3/S1, together with the other four upregulated srRNAs (MicF, a ribosome binding inhibitor; MicL, an outer membrane associated srRNA; $\mathrm{RybB}$, a cell envelope stress regulator; RydB, regulator of a global regulator RpoS) in $\mathrm{S} 2 / \mathrm{S} 1$ are of special interest. By constructing deletion mutants and overexpression strains in uropathogenic E. coli strain UTI89, we tested their persister-formation capabilities in log phase and stationary phase cultures exposed to antibiotics (gentamicin, cefotaxime and levofloxacin) and stresses (heat, hyperosmosis, $\mathrm{H}_{2} \mathrm{O}_{2}$, and acid). The results of the deletion mutant studies showed that all the seven identified sRNAs have varying effects on persister formation with different antibiotics or stresses. Moreover, we found all the deletion mutants of these srRNAs have reduced biofilm formation. Additionally, except the McaS and the RydB overexpression strains, all of the srRNAs overexpression strains demonstrated increased persister-formation in antibiotic and stress persister assays, confirming the role of these srRNAs in persistence. Together, we identified seven srRNAs (OmrB, RdlB, McaS, MicF, MicL, RybB, and RydB) that are involved in type II persister 
formation for the first time. These findings provide convincing evidence for a new level of rapid persistence regulation via srRNA and furnish novel therapeutic targets for intervention.

Keywords: small RNA, persister, antibiotic, stress, uropathogenic Escherichia coli, biofilm

\section{Introduction}

Persisters have drawn wide attention since they can be identified in almost every bacterial species, even in fungi and eukaryotic human cancer cells [1-5]. They refer to a small subpopulation of dormant cells that can survive lethal antibiotics or stresses and regain susceptibilities when regrowing in fresh medium [6-8]. Persisters account for the recalcitrance of treatment of many persistent bacterial infections and can facilitate the emergence of antibiotic resistant bacteria [7-11]. Consequently, persisters pose great challenges for effective treatment of many bacterial infections

Persisters are divided into, type I and type II persisters [12]. Type I persisters stem from the stationary phase, while type II persisters are induced by triggering environmental signals as the cultures grow older from log phase to stationary phase. Unlike type I persister, type II persisters make up a great majority of the persisters in the stationary phase [13] and we consider them very important for understanding persister-formation mechanisms. Although various persister genes have been identified, how persisters are formed from a growing cell to a persister cell is still unclear.

Small regulatory RNAs (srRNAs) are widely spread in three domains of life, Archaea, Bacteria, and Eukaryotes [14]. In Escherichia coli (E. coli), they are non-coding, 50-500 nucleotides in length and synthesized under specific conditions [15-17]. srRNAs function in stress response, virulence regulation, biofilm formation, cell motility, uptake and metabolisms [18-22]. Though various functions have been described, their roles in persistence remain unclear. It is critical to determine the persister-formation capacities of srRNAs as they can respond to external signals quickly without protein synthesis.

To study the role of srRNA in persistence, especially those related with the emergence of type II persisters, we systematically interrogated the expression levels of the known srRNAs at three important timepoints where persisters switch from zero to high numbers. By constructing deletion mutants and overexpression strains of the candidate srRNAs and challenging them with different antibiotics and stresses, we identified seven srRNAs which play critical roles in regulating persister-formation.

\section{Materials and methods}




\section{Bacterial strains, plasmids, and growth conditions}

E. coli K12 strain W3110 and uropathogenic E. coli strain UTI89 as well as its derivatives were used in our experiments. The plasmid pBAD202 was used to construct the overexpression strains. The medium was supplemented with kanamycin (50 $\mu \mathrm{g} / \mathrm{mL})$ or chloramphenicol $(25 \mu \mathrm{g} / \mathrm{mL})$ to maintain resistance where necessary. Bacteria stored in $-80^{\circ} \mathrm{C}$ were transferred to fresh Luria-Bertani (LB) broth $(10 \mathrm{~g}$ Bacto-tryptone, $5 \mathrm{~g}$ yeast extract, and $10 \mathrm{~g} \mathrm{NaCl} /$ liter) at $37^{\circ} \mathrm{C}, 200 \mathrm{rpm}$ and grew overnight before use. Bacteria were diluted 1:1000 and routinely regrown in LB broth at $37^{\circ} \mathrm{C}, 200 \mathrm{rpm}$ in our experiments, unless otherwise stated.

\section{Construction of deletion mutants and overexpression strains}

sRNA deletion mutants were constructed successfully using the $\lambda$ Red recombination system as described by Datsenko and Wanner [23]. Primers used to amplify all knockout-DNA fragments and to verify the correct constructs by polymerase chain reaction (PCR) are shown in Tables S1and S2.

The arabinose-inducible plasmid pBAD202 was used to construct overexpression strains [24]. The primers used for the construction of the plasmid are listed in Table S3. Genes were amplified with primers and digested with the restriction enzymes NcoI and EcoRI (New England Biolabs). pBAD202 was also digested with the two enzymes and used for ligation with the PCR fragments using the T4 DNA ligase (New England Biolabs). The new constructs along with the empty vector, pBAD202, were transformed into parent strain UTI89 for overexpression experiments. The deletion mutants and overexpression strains were verified by DNA sequencing. Arabinose $(0.1 \%)$ was added to the cultures of overexpression strains to induce the conditional expression of candidate genes [3].

\section{RNA isolation and quantitative real time-PCR (RT-PCR)}

Bacteria were routinely cultured in LB medium followed by centrifugation at $4{ }^{\circ} \mathrm{C}$, $5000 \mathrm{rpm}$ to remove the supernatant. RNAprotect Bacteria Reagent (Qiagen) was added to resuspended cell suspensions immediately. Total RNA was isolated from cells using bacterial RNA kit (Omega Bio-tek) according to the manufacturer's protocol. Standardized total RNA was converted to cDNA using PrimeScript TMRT reagent Kit with gDNA Eraser (Takara) as described by the manufacturer. cDNA was then used as template to perform RT-PCR on an Applied Biosystems 7500 real-time instrument. The $16 \mathrm{~S}$ rRNA gene $r r s B$ was used as the reference gene.

\section{Persister assay}

Persister levels were determined by counting the number of colony forming units (CFUs) that grew on LB agar plates without antibiotics following exposure to 
antibiotics, washing, and serial dilutions as previously described [3]. The antibiotics levofloxacin $(5 \mu \mathrm{g} / \mathrm{mL})$, cefotaxime $(128 \mu \mathrm{g} / \mathrm{mL})$, gentamicin $(30 \mu \mathrm{g} / \mathrm{mL})$ were added directly to cultures at the exponential phase ( $3 \mathrm{~h}$ of cultivation, $\sim 10^{8} \mathrm{CFU} / \mathrm{mL}$ ) or stationary phase ( $10 \mathrm{~h}$ of cultivation, $\left.\sim 10^{9} \mathrm{CFU} / \mathrm{mL}\right)$. Aliquots of the bacterial cultures were incubated at $37^{\circ} \mathrm{C}$ at different time points. To determine $\mathrm{CFU}$, cultures were washed in phosphate-buffered saline before plating on LB plates in the absence of antibiotics [25].

\section{Susceptibility to other stresses in exposure assays}

For acid stress ( $\mathrm{pH}$ 3.0) and hyperosmosis stress $(\mathrm{NaCl}, 4 \mathrm{M})$, cultures were washed twice and resuspended in the same volume of the corresponding LB medium ( $\mathrm{pH} 3.0$, adjusted with $\mathrm{HCl}$ or $\mathrm{NaCl}, 4 \mathrm{M}$, respectively). For heat shock, bacteria were put in a water bath at $53^{\circ} \mathrm{C}$ for $1 \mathrm{~h}$ or $2 \mathrm{~h}$. For the oxidative stress test, stationary phase cultures were diluted 1:100 with $\mathrm{LB}$ and exposed to hydrogen peroxide $\left(\mathrm{H}_{2} \mathrm{O}_{2}\right)$ at a final concentration of $10 \mathrm{mM}$ for up to 30 minutes. After exposure to various stresses, bacteria were washed in phosphate-buffered saline before plating on LB plates in the absence of antibiotics to determine CFU count $[25,26]$.

\section{Biofilm assay}

Biofilm assays were performed as described previously [27]. Overnight cultures grown in LB were diluted to $\mathrm{OD}_{600}$ of $\sim 0.05$ in LB. A $200 \mu$ laliquot of the diluted culture was added to each well of a 96-well polystyrene microtiter plate (Sermo, USA) and inoculated at $37^{\circ} \mathrm{C}$ without shaking for $24 \mathrm{~h}$. The planktonic cells were determined by measuring $\mathrm{OD}_{600}$ using the SpectraMax Paradigm multi-mode detection platform (Applied Biosystems). The plate was washed with distilled water to remove the planktonic cells and retained with $220 \mu$ of $0.1 \%$ crystal violet for 10 min. Unattached dye was rinsed away by washing with water for three times. Then the plate was dried and added with acetic acid (30\%) to solubilize fixed crystal violet. The fixed biofilms were detected at $\mathrm{OD}_{570}$ and normalized by $\mathrm{OD}_{600}$.

\section{Statistical analysis}

All experiments were performed at least in triplicate. The Mann-Whitney $U$ test (non - parametric tests) in Prism 6.0 software (GraphPad, La Jolla, CA, USA) was used to analyze the data (UTI89 vs. mutants) to determine the statistical significance of differences [28]. Error bars indicated standard deviations, and all data were presented as the mean \pm standard deviation. A $P<0.05$ was considered statistically significant.

\section{Results}

\section{Determination of three timepoints for type II persisters upon ampicillin} treatment 
Type II persisters are induced by fluctuating environmental signals, not originated from passage through the stationary phase [12]. Thus, capturing the timepoints that type II persisters appear and increase significantly is very important to study the genes involved in type II persister formation. In order to minimize interference with type I persisters, E. coli strain W3110 overnight cultures were diluted to a very high dilution $1: 10^{5}$ into fresh LB medium and then incubated at $37^{\circ} \mathrm{C}$, with shaking at $100 \mathrm{rpm}$. Aliquots of bacteria were removed and exposed to ampicillin $(100 \mu \mathrm{g} / \mathrm{mL})$ for 3 hours to determine the persister numbers. We found that no persisters existed in the first three hours. However, persisters started to appear at the $4^{\text {th }}$ hour, with $2 \sim 3 \mathrm{CFU} / \mathrm{mL}$ being detected. At the $5^{\text {th }}$ hour, the persister number increased to $\sim 42 \mathrm{CFU} / \mathrm{mL}$ (Fig. 1A). Meanwhile, the initial cell numbers at the $3^{\text {rd }}, 4^{\text {th }}$ and $5^{\text {th }}$ hours were also counted, with bacterial concentration reaching $\sim 2.1 \times 10^{5}, \sim 1.4 \times 10^{6}, \sim 1.1 \times 10^{7}$ respectively (Fig. 1B). Results indicated that cell density is associated with the emergence of persisters. We referred to the $3^{\text {rd }}$ hour as stage 1 (S1) where no persisters were present at this time point. The $4^{\text {th }}$ hour is referred to as stage 2 (S2) where persisters were just beginning to appear, and the $5^{\text {th }}$ hour is referred to as stage 3 (S3) where persister numbers increased significantly at this timepoint. S1, S2 and S3 are three important timepoints we used to identify genes associated with type II persister formation (see below).

\section{Different expression levels of small regulatory RNAs in S1, S2, S3}

To study the expression levels of srRNAs at the timepoints when persisters first appeared and then increased, we determined the expression levels of all the 57 srRNAs in the comprehensive EcoCyc database [29]. We found eight upregulated srRNAs (MicF, MgrR, MicL, OmrB, RdlB, McaS, RybB, RydB) (Fig. 2A) and 16 downregulated srRNAs (DicF, GadY, GlmZ, GlmY, IstR-1, OxyS, SgrS, SymR, SsrS, ArrS, FnrS, Och5, OhsC, RyfA, RyfD, RyeB) when comparing expression levels of S2 with S1. Six upregulated srRNAs (OmrB, RseX, McaS, MgrR, MicA, RdlB) (Fig. 2B) and 17 downregulated srRNAs (GadY, GlmZ, GlmY, IstR-1, OmrA, OxyS, RdlD, RybB, SgrS, SsrS, FnrS, Och5, RyfA, RyfD, RyeB, SibD, SibE) were detected when comparing expression levels of S3 with S1. Similarly, three upregulated srRNAs (DicF, ArrS, RyeG) and seven downregulated srRNAs (DsrA, GadY, RdlD, RybB, RydB, RyfA, SibE) were observed when comparing expression levels of S3 with S2. Target genes with known functions of the upregulated srRNAs are shown in Table 1. Pathways of these target genes comprise energy production, transport system, TA module, biofilm formation, global regulator, protease, trans-translation system, efflux pump that belong to known persister pathways [7], indicating the upregulated srRNAs might participate in persister formation.

\section{Susceptibility of the srRNA deletion mutants to different antibiotics}

To determine the role of the seven upregulated srRNAs in persistence, we constructed their deletion mutants $(\Delta m i c F, \Delta o m r B, \Delta r y b B, \Delta m c a S, \Delta m i c L, \Delta r d l B, \Delta r y d B)$ in the 
uropathogenic E. coli strain UTI89 and tested their persister phenotypes to different classes of antibiotics. We monitored the numbers of the parent strain and all the deletion mutants without any antibiotic or stress exposure from the beginning to the end of the experiments and no difference was observed between the parent strain and the mutant strains (data not shown). In the $\log$ phase cultures $\left(\sim 10^{8} \mathrm{CFU} / \mathrm{mL}\right)$, when all the bacteria were challenged with gentamicin $(30 \mu \mathrm{g} / \mathrm{mL}), \Delta m c a S, \Delta r y d B$ and $\Delta$ micL mutants showed decreased persister numbers, ranging from 7 -fold $(\Delta m i c L)$ to 10-fold $(\Delta \mathrm{mcaS})$ difference compared with the parent strain, whereas the other mutants were not affected (Fig. 3A). When exposed to cefotaxime (128 $\mu \mathrm{g} / \mathrm{mL}$ ), all the mutants showed a decrease in persistence compared with the parent strain UTI89, ranging from 8-fold $(\Delta r d l B)$ to 170 -fold $(\Delta m c a S)$ (Fig. 3B). The log phase cultures were also treated with levofloxacin for $0.5 \mathrm{~h}$, and there was about 5-log decrease in all the tested strains, with no difference observed between the deletion mutants and the parent strain (data not shown).

However, when the stationary phase cultures were exposed to levofloxacin for two days, the persister phenotype could be observed. $\triangle r y d B$ mutant showed a dramatic increase in persistence (Fig. 3C). After exposure to levofloxacin for six days, it could be observed that another deletion mutant $(\triangle r y b B)$ had a decreased persister phenotype (Fig. 3D), indicating $r y b B$ could be a late persister gene. When the seven srRNAs deletion mutants were treated with gentamicin for two days, $\triangle r y b B$ and $\Delta m i c F$ mutants had prominent decrease in persistence compared to the parent strain UTI89 (Fig. 3E), while the $\Delta o m r B$ mutant demonstrated persister defect at day 3 (Fig. 3F). After exposure to cefotaxime, the $\Delta m i c L$ mutant showed defect in persister formation, whereas the $\triangle r y d B$ mutant showed increased persister-formation level at day 4 (Fig. $3 \mathrm{G})$. The $\Delta o m r B$ mutant also had lower persister number upon cefotaxime treatment at day 6 (Fig. $3 \mathrm{H})$.

\section{Susceptibility of the srRNA deletion mutants to stresses}

To determine the effect of stresses on the survival of the srRNA deletion mutants, we subjected all the seven mutants to hyperosmosis $(\mathrm{NaCl}, 4 \mathrm{M})$, acid $(\mathrm{pH} 3.0)$, heat $\left(53^{\circ} \mathrm{C}\right)$ and oxidative $\left(\mathrm{H}_{2} \mathrm{O}_{2}, 10 \mathrm{mM}\right)$ stresses and assessed their survival in the stationary phase (Fig. 4). Upon exposure to hyperosmosis for five days, only the $\Delta m i c L$ mutant showed dramatic decrease in survival (208-fold decrease) compared with the parent strain UTI89. No difference could be observed between the other deletion mutant strains and the parent strain (Fig. 4A). When treated with acid, four deletion mutants ( $\triangle m i c L, \Delta o m r B, \Delta r d l B, \Delta r y b B)$ showed higher susceptibilities (at least 16-fold decrease) compared with the parent strain, while the other three deletion mutants $(\Delta m i c F, \Delta m c a S, \Delta r y d B)$ had similar susceptibilities as the parent strain (Fig. 4B). Upon exposure to heat, five deletion mutants ( $\Delta m i c L, \Delta o m r B, \Delta m i c F, \Delta r d l B$, $\triangle r y b B$ ) showed higher susceptibilities (at least 13-fold decrease) when compared with the parent strain (Fig. 4C). When all the deletion mutants were subjected to $\mathrm{H}_{2} \mathrm{O}_{2}$ oxidative stress, the survival of the five deletion mutant strains $(\Delta r d l B, \Delta m i c L, \Delta r y d B$, 
$\Delta m i c F, \Delta m c a S)$ was significantly decreased, whereas the other two mutants $(\Delta o m r B$, $\Delta r y b B$ ) showed the same magnitude of decrease as the parent strain (Fig. 4D).

\section{Effects of the overexpression of srRNAs on persister levels}

The seven srRNAs $(\Delta m i c F, \Delta o m r B, \Delta r y b B, \Delta m c a S, \Delta m i c L, \Delta r d l B, \Delta r y d B)$ were overexpressed to further characterize their effects on persistence. The newly constructed plasmids carrying the corresponding srRNAs along with the empty vector pBAD202 were transformed into parent strain UTI89 for construction of the overexpression strains. In the stationary phase cultures, we found the five srRNAs (MicF, MicL, OmrB, RdlB, RybB) overexpression strains showed higher persister levels than the control strain upon exposure to levofloxacin $(5 \mu \mathrm{g} / \mathrm{mL})$, gentamicin $(30 \mu \mathrm{g} / \mathrm{mL})$, cefotaxime $(128 \mu \mathrm{g} / \mathrm{mL})$ and various stresses hyperosmosis $(\mathrm{NaCl}, 4 \mathrm{M})$, acid $(\mathrm{pH}, 3.0)$, heat $\left(53^{\circ} \mathrm{C}\right)$, and oxidative stress $\left(\mathrm{H}_{2} \mathrm{O}_{2}, 10 \mathrm{mM}\right)$, respectively. However, the RydB overexpression strain resulted in decreased persister levels to levofloxacin, cefotaxime, hyperosmosis and heat exposure, but showed increased persister levels to gentamicin, acid and oxidation treatment. The McaS overexpression strain also demonstrated higher persister-formation capabilities to levofloxacin, cefotaxime, gentamicin and stresses hyperosmosis, acid and oxidation exposure, whereas it had defect when challenged with heat stress (Table 2-3). Overall, all of the seven srRNAs have varying effects on persister-formation when overexpressed.

\section{Impact of the srRNA mutations on biofilm formation}

Because the presence of persister cells in the biofilm contributes largely to the recalcitrance to antibiotic treatment [30-33], we determined the influence of the persister-associated srRNAs on biofilm-formation. Interestingly, the results showed all the deletion mutants $(\Delta m i c F, \Delta o m r B, \Delta r y b B, \Delta m c a S, \Delta m i c L, \Delta r d l B, \Delta r y d B)$ had reduced biofilm formation to some degree compared with the parent strain UTI89 (Fig. 5). Among them, the $\Delta m c a S$ mutant was the weakest ( 21\% decrease) while the $\Delta m i c F$ mutant had the strongest effect on biofilm formation ( $40 \%$ decrease) compared with the parent strain UTI89.

\section{Discussion}

In this study, we identified seven novel srRNAs (MicF, OmrB, RybB, McaS, MicL, $\mathrm{RdlB}, \mathrm{RydB}$ ) associated with persister formation in the uropathogenic E. coli strain UTI89. To our knowledge, this is the first study that comprehensively characterized the role of srRNA in persister formation. By comparing different expression levels of srRNAs in the three important timepoints S1, S2 and S3 relevant to persister formation, we identified initial natural persister formation related srRNAs (MicF, OmrB, RybB, McaS, MicL, RdlB, RydB) in the absence of antibiotic background. Because persisters are produced by a stochastic process $[8,34]$, monitoring the expression levels of genes after antibiotic treatment to search for persister-associated 
genes is not suitable, as genes could be induced by antibiotics thereby confounding the real important persister formation genes [35]. By using this new persister gene search methodology comparing the expression of srRNAs at different critical stage of no persister and persister emergence in our study, we were able to find seven native srRNAs (MicF, OmrB, RybB, McaS, MicL, RdlB, RydB) involved in type II persister formation.

Apart from their roles in exponential phase persister-formation (Fig. 3A, 3B ), we found the seven srRNAs are also involved in persistence in stationary phase (Fig. 3C-3H, Fig. 4 and Table 2-3). This phenomenon suggests that srRNAs fulfill their persistence function in the whole life span of the bacteria and confirms that srRNAs play a vital role in persistence to different antibiotics and stresses.

McaS is a multi-cellular adhesive small regulatory RNA and is known to regulate flagellar motility and biofilm formation by targeting the global transcription regulators $(\operatorname{csg} D, f l h D)$ and biofilm formation related mRNA pgaA [27, 36]. Protein co-purification study also found that McaS could bind with RpsA (translation initiation factor), Lon (DNA-binding ATP-dependent protease), PNPase (polynucleotide phosphorylase or - polymerase), AtpA (F1 sector of membrane-bound ATP synthase), CsrA (Regulatory McaS protein for carbon source metabolism) [37]. The targets of McaS match well to the known persister pathways including global regulator, biofilm formation, trans-translation, protease and energy production [7], which can count for the role of McaS in persistence. Notably, Lon protease can also be regulated by McaS. As we know, polyphosphated Lon protease can cause the degradation of antitoxins and the freed toxin, subsequently turning bacteria into dormant persisters $[38,39]$. This suggests that McaS may also influence TA modules for persister formation.

MicF inhibits ribosome binding and induce the degradation of the RNA messages in many bacteria [40]. MicF can interact with $\operatorname{lrp}$ (a global regulator involved in amino acid biosynthesis and catabolism), and down-regulate translation of ompF (outer membrane porin), soxS (DNA-binding transcriptional dual regulator) and tolC (a central factor involved in efflux pump) [41], which can be important for persister formation and survival $[41,42]$. By serving as a well known antisense RNA of $o m p F$, MicF can down-regulate $o m p F$ to reduce the entry of antibiotics so persisters can survive. Pathways of these targets are involved in global regulator, biofilm formation and efflux pump activity. We propose that MicF may influence the persister pathways to cause persistence to antibiotics and stresses via its target genes. It has been shown different expression levels of MicF in response to osmolarity and temperature change [43], and our observation that MicF mutant has defective persistence to hyperosmosis and heat exposure is consistent with the previous study.

MicL was reported to have a sole target lpp, an abundant outer membrane lipoprotein in response to stress [44]. We suppose that MicL may influence lpp expression to 
affect transport of antibiotics and other stressors, thus facilitating persistence. In addition, using the updated tools CopraRNA and IntaRNA software for small RNA target prediction [45], we found MicL has binding sites with mazF (mRNA interferase toxin antitoxin) and hipB (HipB antitoxin / DNA-binding transcriptional repressor), which are two known persister genes involved in TA modules, indicating that MicL could mediate persister formation via these antitoxins.

RybB can regulate the expression of membrane porins related mRNA (ompC, ompD, omp $W$, ompF , and $f a d L$ ) [46, 47], a transcriptional regulator associated with biofilm formation (csgD) [48], and also modulate LPS biosynthesis [49]. Additionally, overexpression of $r y b B$ causes increased expression of $r p o S$ (a global regulator involved in persister formation) [50] and decreased levels of fumC (a fumarase isozyme participating in the TCA cycle) [46]. Thus, the targets of RybB match known persister pathways including those of biofilm formation, global regulators, and energy production [7], which could all account for persister phenotype of RybB.

The $o m r B$ deletion mutant showed defect in persistence when challenged with multiple antibiotics and stresses in both exponential phase and stationary phase cultures (Fig. 3-4). OmrB is known to regulate the expression levels of genes encoding many outer membrane proteins, including $\operatorname{cir} A, f e c A, f e p A$ and $о т p T$, ompR [51], which could modulate outer membrane composition in response to environmental stress conditions. In addition, two transcriptional regulators $\operatorname{csg} D$ (important for biofilm formation) and $f l h D C$ together with a gluconate /fructuronate transporter gntP could also be modulated by OmrB [51-53]. Thus, we propose that OmrB can affect different persister pathways involved in biofilm, translational regulator and transport system to perform its persister function via its target genes.

To date, little is known about the functions of RdlB except that overexpression of RdlB decreases swarming motility and curli expression [54]. In this study, we demonstrated that RdlB is involved in persistence to antibiotics (levofloxacin, gentamicin, cefotaxime) and stresses (hyperosmosis, heat, oxidation, acid) for the first time (Fig. 3-4, Table 2-3). In order to investigate the mechanisms involved, we used the updated tools CopraRNA and IntaRNA for RdlB target prediction [45]. Results showed that RdlB has binding sites with energy production mRNA srmB (ATP-dependent RNA helicase), paaH (3-hydroxyadipyl-CoA dehydrogenase NAD+-dependent), transport system mRNA nirC (nitrite transporter), ssuB (aliphatic sulfonate $\mathrm{ABC}$ transporter ATPase), potH (putrescine ABC transporter permease), nirD (nitrite reductase NADH small subunit) and membrane associated mRNA $y b h M$ (BAX Inhibitor-1 family inner membrane protein), yiaT (putative outer membrane protein), pqiA (inner membrane protein) as well as DNA repair mRNA vsr (DNA mismatch endonuclease of very short patch repair). The associated pathways of these targets are known to be associated with persistence [7]. Notably, RdlB could also bind to thaA, a well-known persister gene connected to signaling pathway. Future studies are needed to confirm how RdlB is involved in persister formation. 
So far, RydB is known to regulate $r p o S$ (a global regulator involved in persister formation) expression only [55]. In our study, we found RydB could modulate persister formation when treated with antibiotics and lethal stresses. Using small RNA target prediction CopraRNA and IntaRNA software analysis [45], we found RydB could affect persister pathways [7] via energy production mRNA $s d h A$ (succinate dehydrogenase flavoprotein subunit), purC (amidophosphoribosyltransferase), yjfC (ATP-Grasp family ATPase), $c b r A$ (FAD-binding protein putative oxidoreductase), membrane associated mRNA $y b b J$ (inner membrane protein), asmA (inner membrane-anchored), $y i h G$ (inner membrane protein inner membrane acyltransferase), yobD (UPF0266 family inner membrane protein), transport system mRNA yncD (putative iron outer membrane transporter), art $Q$ (arginine $\mathrm{ABC}$ transporter permease), $\mathrm{fec} C$ (ferric citrate $\mathrm{ABC}$ transporter permease), satP (succinate-acetate transporter), efflux pump mRNA $m d t C$ (multidrug efflux system subunit C), $y d h K$ (putative efflux protein, component of YdhJK efflux pump) and trans-translation system rpsA mRNA. Among them, sdhA and $r p s A$ are known persister genes $[56,57]$.

Biofilm can resist antibiotic killing without any drug resistance mechanisms. The link between the presence of persisters and biofilm formation is the subject of many studies [31, 32, 58, 59]. We propose that the roles of the srRNAs in persistence are associated with their biofilm formation capability, based on our findings. In line with this proposition, we found that the deletion mutants of the seven srRNAs all showed defective biofilm formation (Fig. 5). In particular, our finding of McaS is consistent with the previous finding that McaS is associated with biofilm formation [27]. However, the impacts of srRNA on attachment and secretion of extracellular polymeric substances to the biofilm remains further study.

In summary, we identified seven new small regulatory RNAs (OmrB, RdlB, McaS, $\mathrm{MicF}$, MicL, RybB, and RydB) that are involved in persister formation using a novel persister gene search methodology. The targets of these small regulatory RNAs involved in several persister pathways including energy production, transport system, SOS response, DNA repair, TA module, biofilm formation, global regulator, trans-translation system, and efflux pump. Future studies are needed to address the role of srRNAs in persister formation in other bacteria and in vivo as well as the exact mechanisms by which srRNAs regulate the persistence phenomenon. Our findings provide new insights into mechanisms of persister formation and its regulation at the srRNA level and offer new targets for treatment of persistent infections.

\section{Conflict of Interest Statement}

The authors declare that this research was conducted in the absence of any commercial or financial relationships that could be construed as a potential conflict of interest. 


\section{Author Contributions}

YZ, WZ designed the experiments and revised the manuscript; SZ and SL completed all the experiments, SZ and NW performed the data analysis; SZ and YZ wrote the manuscript.

\section{Acknowledgments}

We thank Peng Cui, Tao Xu, Jing Wu and Jiazhen Chen, at Department of Infectious Diseases, Huashan Hospital, China for helpful advice in data analysis. The research was supported by the National Natural Science Foundation of China (81572046).

Table 1. Target genes of the upregulated srRNAs.

\begin{tabular}{|c|c|c|c|}
\hline $\begin{array}{l}\text { SrRNA } \\
\text { Name }\end{array}$ & $\begin{array}{l}\text { Target gene } \\
\text { name }\end{array}$ & Description of target gene & $\begin{array}{l}\text { Pathway of } \\
\text { target gene }\end{array}$ \\
\hline \multirow[t]{9}{*}{$\mathrm{MicF}$} & $\operatorname{lrp}$ & $\begin{array}{l}\text { DNA-binding transcriptional dual } \\
\text { regulator }\end{array}$ & global regulator \\
\hline & ompF & outer membrane porin $\mathrm{F}$ & biofilm formation \\
\hline & tolC & outer membrane channel TolC & efflux pump \\
\hline & cptA & membrane-associated protein & TA module \\
\hline & $h s d S$ & $\begin{array}{l}\text { type I restriction enzyme EcoKI } \\
\text { specificity protein }\end{array}$ & \\
\hline & $z w F$ & $\mathrm{NADP}^{+}$-dependent & energy production \\
\hline & & glucose-6-phosphate dehydrogenase & \\
\hline & phoE & outer membrane porin $\mathrm{E}$ & biofilm formation \\
\hline & $\operatorname{soxS}$ & $\begin{array}{l}\text { DNA-binding transcriptional dual } \\
\text { regulator }\end{array}$ & global regulator \\
\hline MicL & lpp & murein lipoprotein & \\
\hline MgrR & eptB & phosphoethanolamine transferase & \\
\hline \multirow[t]{6}{*}{ OmrB } & ompR & $\begin{array}{l}\text { DNA-binding transcriptional dual } \\
\text { regulator }\end{array}$ & biofilm formation \\
\hline & ompT & Outer membrane protease VII & biofilm formation \\
\hline & $\operatorname{cirA}$ & $\begin{array}{l}\text { ferric dihyroxybenzoylserine outer } \\
\text { membrane transporter }\end{array}$ & transport system \\
\hline & fecA & $\begin{array}{l}\text { ferric citrate outer membrane } \\
\text { transporter }\end{array}$ & transport system \\
\hline & fepA & $\begin{array}{l}\text { ferric enterobactin outer membrane } \\
\text { transporter }\end{array}$ & transport system \\
\hline & $f l h D C$ & DNA-binding transcriptional dual & biofilm formation \\
\hline
\end{tabular}




\begin{tabular}{|c|c|c|c|}
\hline & & regulator & \\
\hline & gntP & fructuronate transporter & transport system \\
\hline & $\operatorname{csg} D$ & $\begin{array}{l}\text { DNA-binding transcriptional dual } \\
\text { regulator }\end{array}$ & biofilm formation \\
\hline \multirow[t]{9}{*}{ McaS } & $\operatorname{csg} D$ & $\begin{array}{l}\text { DNA-binding transcriptional dual } \\
\text { regulator }\end{array}$ & biofilm formation \\
\hline & $\operatorname{csr} A$ & carbon storage regulator & global regulator \\
\hline & $f l h D$ & $\begin{array}{l}\text { DNA-binding transcriptional dual } \\
\text { regulator }\end{array}$ & biofilm formation \\
\hline & $\operatorname{pgaA}$ & $\begin{array}{l}\text { partially } N \text {-deacetylated } \\
\text { poly- } \beta-1,6-N \text {-acetyl-D-glucosamine } \\
\text { outer membrane porin }\end{array}$ & biofilm formation \\
\hline & rpsA & 30 S ribosomal subunit protein $\mathrm{S} 1$ & trans-translation \\
\hline & lon & Lon protease & protease \\
\hline & $p n P$ & polynucleotide phosphorylase & energy production \\
\hline & $\operatorname{atp} A$ & ATP synthase $\mathrm{F}_{1}$ complex subunit $\alpha$ & energy production \\
\hline & $s d A$ & cysteine sulfinate desulfinase & \\
\hline \multirow[t]{8}{*}{ RybB } & waaR & UDP-glucose:(glucosyl) LPS & energy production \\
\hline & & $\alpha$-1,2-glucosyltransferase & \\
\hline & rpos & $\begin{array}{l}\text { RNA polymerase, sigma } S \text { (sigma } \\
\text { 38) factor }\end{array}$ & global regulator \\
\hline & $\operatorname{csg} D$ & $\begin{array}{l}\text { DNA-binding transcriptional dual } \\
\text { regulator }\end{array}$ & biofilm formation \\
\hline & rpoE & $\begin{array}{l}\text { RNA polymerase, sigma } 24 \text { (sigma } \\
\text { E) factor }\end{array}$ & global regulator \\
\hline & $\begin{array}{l}\text { ompC,D, F, } \\
W\end{array}$ & outer membrane porinC, D, F, W & biofilm formation \\
\hline & fadL & $\begin{array}{l}\text { long-chain fatty acid outer } \\
\text { membrane porin }\end{array}$ & energy production \\
\hline & fumC & fumarase $\mathrm{C}$ & energy production \\
\hline RydB & rpos & $\begin{array}{l}\text { RNA polymerase, sigma } S \text { (sigma } \\
\text { 38) factor }\end{array}$ & global regulator \\
\hline RseX & ompA,C & outer membrane porin A, $C$ & biofilm formation \\
\hline \multirow[t]{3}{*}{ MicA } & ompA,X & outer membrane porin $\mathrm{A}, \mathrm{X}$ & biofilm formation \\
\hline & phoP & $\begin{array}{l}\text { DNA-binding transcriptional dual } \\
\text { regulator }\end{array}$ & global regulator \\
\hline & phoQ & bifunctional sensory histidine kinase & \\
\hline \multirow[t]{4}{*}{$\mathrm{DicF}$} & $f t s Z$ & cell division protein & \\
\hline & $x y l R$ & $\begin{array}{l}\text { DNA-binding transcriptional dual } \\
\text { regulator }\end{array}$ & global regulator \\
\hline & pykA & pyruvate kinase II & energy production \\
\hline & $r p o S$ & $\begin{array}{l}\text { RNA polymerase, sigma } S \text { (sigma } \\
\text { 38) factor }\end{array}$ & global regulator \\
\hline ArrS & $\operatorname{gad} E$ & DNA-binding transcriptional & global regulator \\
\hline
\end{tabular}




\begin{tabular}{lll}
\hline & & activator \\
RyeG & Unknown & \\
RdlB & Unknown & \\
\hline
\end{tabular}

Table 2. Effect of overexpression of srRNAs on persister levels upon antibiotic exposure

\begin{tabular}{lclll}
\hline \multirow{2}{*}{$\begin{array}{l}\text { Overexpression } \\
\text { strains }\end{array}$} & \multicolumn{4}{l}{ No. of bacteria (Log CFU/mL) } \\
\cline { 2 - 5 } & $\begin{array}{l}\text { Starting } \\
\text { CFU }\end{array}$ & LVX & GEN & CTX \\
\hline UTI89-Pvector & $9.4 \pm 0.12$ & $3.3 \pm 0.21$ & $2.5 \pm 0.45$ & $6.1 \pm 0.09$ \\
UTI89-PmcaS & $9.8 \pm 0.05$ & $5.3 \pm 0.07$ & $4.2 \pm 0.13$ & $7.9 \pm 0.13$ \\
UTI89-PrdlB & $9.7 \pm 0.05$ & $6.0 \pm 0.02$ & $4.6 \pm 0.08$ & $8.0 \pm 0.10$ \\
UTI89-PrydB & $9.7 \pm 0.04$ & $2.2 \pm 0.18$ & $5.3 \pm 1.55$ & 0 \\
UTI89-PomrB & $9.8 \pm 0.02$ & $6.1 \pm 0.06$ & $3.9 \pm 0.28$ & $8.1 \pm 0.02$ \\
UTI89-PmicL & $9.8 \pm 0.02$ & $5.4 \pm 0.63$ & $4.0 \pm 0.42$ & $7.8 \pm 0.03$ \\
UTI89-PrybB & $9.8 \pm 0.03$ & $5.0 \pm 0.14$ & $4.2 \pm 0.09$ & $7.6 \pm 0.06$ \\
UTI89-PmicF & $9.8 \pm 0.03$ & $5.1 \pm 0.13$ & $5.2 \pm 0.12$ & $8.0 \pm 0.04$ \\
\hline
\end{tabular}

395

396

397

398

399

400

401

402

403

Stationary phase bacteria $\left(\sim 10^{9} \mathrm{CFU} / \mathrm{mL}\right)$ were challenged with levofloxacin (LVX, 5 $\mu \mathrm{g} / \mathrm{mL}$ ), gentamicin (GEN, $30 \mu \mathrm{g} / \mathrm{mL}$ ) and cefotaxime (CTX, $128 \mu \mathrm{g} / \mathrm{mL}$ ), respectively, for five days. CFU values were determined at the appropriate times.

Table 3. Effect of overexpression of srRNAs on persister levels upon stress exposure.

\begin{tabular}{lcllll}
\hline & \multicolumn{5}{l}{ No. of bacteria (Log CFU/mL) } \\
\cline { 2 - 6 } $\begin{array}{l}\text { Overexpression } \\
\text { strains }\end{array}$ & $\begin{array}{c}\text { Starting } \\
\text { CFU }\end{array}$ & $\begin{array}{l}\text { Hyper- } \\
\text { osmosis }\end{array}$ & Acid & Heat & $\mathrm{H}_{2} \mathrm{O}_{2}$ \\
\hline UTI89-Pvector & $9.4 \pm 0.12$ & $3.6 \pm 0.41$ & $2.8 \pm 0.06$ & $3.9 \pm 0.17$ & $4.1 \pm 0.17$ \\
UTI89-PmcaS & $9.8 \pm 0.05$ & $7.8 \pm 0.40$ & $4.0 \pm 0.08$ & $2.0 \pm 0.25$ & $5.9 \pm 0.22$ \\
UTI89-PrdlB & $9.7 \pm 0.05$ & $7.7 \pm 0.26$ & $4.0 \pm 0.09$ & $4.4 \pm 0.13$ & $4.9 \pm 0.20$ \\
UTI89-PrydB & $9.7 \pm 0.04$ & $1.0 \pm 0.68$ & $3.5 \pm 0.15$ & $2.2 \pm 0.80$ & $5.1 \pm 0.08$ \\
UTI89-PomrB & $9.8 \pm 0.02$ & $7.8 \pm 0.52$ & $3.9 \pm 0.08$ & $5.5 \pm 0.13$ & $4.9 \pm 0.28$ \\
UTI89-PmicL & $9.8 \pm 0.02$ & $8.0 \pm 0.55$ & $3.8 \pm 0.16$ & $6.0 \pm 0.18$ & $4.9 \pm 0.25$ \\
UTI89-PrybB & $9.8 \pm 0.03$ & $7.7 \pm 0.49$ & $4.1 \pm 0.08$ & $5.6 \pm 0.07$ & $5.3 \pm 0.85$ \\
UTI89-PmicF & $9.8 \pm 0.03$ & $7.8 \pm 0.86$ & $3.6 \pm 0.07$ & $5.5 \pm 0.20$ & $4.9 \pm 0.14$ \\
\hline
\end{tabular}

Stationary phase bacteria $\left(\sim 10^{9} \mathrm{CFU} / \mathrm{mL}\right)$ were directly treated with various stresses. For hyperosmosis or acid $\mathrm{pH}$ stress, the stationary phase bacteria were harvested, washed and then resuspended in hyperosmotic $\mathrm{LB}$ medium $(\mathrm{NaCl}, 4 \mathrm{M})$ for three days as well as in acid LB medium $(\mathrm{pH}, 3.0)$ for one day. For heat, bacteria were directly 
404

405

406

407

408

409

410

411

412

413

414

415

416

417

418

419

420

421

422

423

424

425

426

427

428

429

430

431

432

433

434

435

436

437

438

439

put in a water bath of $53^{\circ} \mathrm{C}$ for one hour. For oxidative stress, bacteria were 1:100 diluted before exposure to $10 \mathrm{mM} \mathrm{H}_{2} \mathrm{O}_{2}$ for 0.5 hour. CFU values were determined at the appropriate times.

\section{Figure legends:}

Fig. 1. Determination of three timepoints for persister formation upon ampicillin treatment. (A) Persister numbers at each hour. Overnight E. coli K-12 W3110 was 1: $10^{5}$ diluted into fresh $\mathrm{LB}$ medium and then incubated at $37^{\circ} \mathrm{C}, 100 \mathrm{rpm}$. At each hour, aliquots were taken and exposed to ampicillin $(100 \mu \mathrm{g} / \mathrm{mL})$ for 3 hours to determine persister numbers. (B) The initial cell count. At the indicated hour, aliquots were taken without any treatment to determine the cell numbers directly. The experiments were performed in triplicate, and error bars represent standard deviations.

Fig. 2. Upregulated small regulatory RNAs in $\mathbf{S 2 / S 1}$ and $\mathbf{S 3} / \mathbf{S 1}$. Overnight $E$. coli $\mathrm{K}-12 \mathrm{~W} 3110$ was $1: 10^{5}$ diluted into fresh $\mathrm{LB}$ medium and then incubated at $37^{\circ} \mathrm{C}, 100$ rpm up to S1 (3 hours), S2 (4 hours) and S3 (5 hours), respectively. And then, total RNA was extracted and used for qRT-PCR. Upregulated small regulatory RNAs when comparing srRNA expression levels in S2/S1 (A), S3/S1 (B) are shown. The error bars show standard deviations $(n=3)$.

Fig. 3. Susceptibility of the srRNA deletion mutants to antibiotics. (A, B) Susceptibilities of the log phase bacteria to gentamicin $(30 \mu \mathrm{g} / \mathrm{mL}, \mathrm{A})$ or cefotaxime $(128 \mu \mathrm{g} / \mathrm{Ml}, \mathrm{B})$ after exposure for six hours. (C, D) Susceptibilities of the stationary phase bacteria to levofloxacin $(5 \mu \mathrm{g} / \mathrm{mL})$ on the second day $(C)$ or the sixth day (D). (E, F) Susceptibilities of the stationary phase bacteria to gentamicin $(30 \mu \mathrm{g} / \mathrm{mL})$ on the second day $(\mathrm{E})$ or the third day $(\mathrm{F}) .(\mathrm{G}, \mathrm{H})$ Susceptibilities of the stationary phase bacteria to cefotaxime $(128 \mu \mathrm{g} / \mathrm{mL})$ on the forth day $(\mathrm{G})$ or the sixth day $(\mathrm{H})$. Bacteria were cultured to log phase $\left(\sim 10^{8} \mathrm{CFU} / \mathrm{mL}\right)$ or stationary phase $\left(\sim 10^{9} \mathrm{CFU} / \mathrm{mL}\right)$ prior to the addition of antibiotics. The number of persisters was determined at the time point indicated in the figure. The error bars show standard deviations $(n=3)$. * Indicates significant difference from the other strains at $p<0.05$.

\section{Fig. 4. Susceptibility of the srRNA deletion mutants to stresses. (A)} Susceptibilities to hyperosmosis ( $\mathrm{NaCl}, 4 \mathrm{M}$ ) after exposure for five days. (B) Susceptibilities to acid ( $\mathrm{pH}$ 3.0) after exposure for one day. (C) Susceptibilities to heat $\left(53^{\circ} \mathrm{C}\right)$ after exposure for two hours. (D) Susceptibilities to oxidative stress $\left(\mathrm{H}_{2} \mathrm{O}_{2}, 10\right.$ $\mathrm{mM})$ after exposure for 0.5 hour. Bacteria were cultured to the stationary phase $\left(\sim 10^{9}\right.$ $\mathrm{CFU} / \mathrm{mL}$ ) prior to the addition of stresses. Detailed methods were described above. The error bars show standard deviations $(n=3) . *$ Indicates significant difference from the other strains at $p<0.05$. 
441

442

443

444

445

446

447

448

449

450

451

452

453

454

455

456

457

458

459

460

461

462

463

464

465

466

467

468

469

470

471

472

473

474

475

476

477

478

479

480

481

482

Fig. 5. Effect of the deletion mutants on biofilm formation. $200 \mu \mathrm{l}$ bacteria were transferred to $96-w e l l$ microtiter plates and grown at $37^{\circ} \mathrm{C}$ for $24 \mathrm{~h}$ in $\mathrm{LB}$ medium. Planktonic cells were measured at $\mathrm{OD}_{600}$. After washing, staining with crystal violet, and dissolution, final biofilm formation was measured at $\mathrm{OD}_{570}$ and normalized to $\mathrm{OD}_{600}$.

\section{References}

1. Bigger, J.W., Treatment of staphylococcal infections with penicillin - By intermittent sterilisation. Lancet, 1944. 2: p. 497-500.

2. Ramirez, M., et al., Diverse drug-resistance mechanisms can emerge from drug-tolerant cancer persister cells. Nature Communications, 2016. 7.

3. Ma, C., et al., Energy production genes sucB and ubiF are involved in persister survival and tolerance to multiple antibiotics and stresses in Escherichia coli. Fems Microbiology Letters, 2010. 303(1): p. 33-40.

4. Ford, A.M., et al., Protracted dormancy of pre-leukemic stem cells. Leukemia, 2015. 29(11): p. 2202-7.

5. Raha, D., et al., The cancer stem cell marker aldehyde dehydrogenase is required to maintain a drug-tolerant tumor cell subpopulation. Cancer Res, 2014. 74(13): p. 3579-90.

6. Dawson, C.C., C. Intapa, and M.A. Jabra-Rizk, "Persisters": Survival at the Cellular Level. Plos Pathogens, 2011. 7(7).

7. Zhang, Y., Persisters, persistent infections and the Yin-Yang model. Emerg Microbes Infect, 2014. 3(1): p. e3.

8. Lewis, K., Persister cells, dormancy and infectious disease. Nature Reviews Microbiology, 2007. 5(1): p. 48-56.

9. Levin-Reisman, I., et al., Antibiotic tolerance facilitates the evolution of resistance. Science, 2017. 355(6327): p. 826-830.

10. Torrey, H.L., et al., High Persister Mutants in Mycobacterium tuberculosis. Plos One, 2016. 11(5).

11. LaFleur, M.D., Q.G. Qi, and K. Lewis, Patients with Long-Term Oral Carriage Harbor High-Persister Mutants of Candida albicans. Antimicrobial Agents And Chemotherapy, 2010. 54(1): p. 39-44.

12. Balaban, N.Q., et al., Bacterial persistence as a phenotypic switch. Science, 2004. 305(5690): p. 1622-5.

13. Keren, I., et al., Persister cells and tolerance to antimicrobials. Fems Microbiology Letters, 2004. 230(1): p. 13-18.

14. Babski, J., et al., Small regulatory RNAs in Archaea. Rna Biology, 2014. 11(5): p. 484-493.

15. Lalaouna, D., et al., Regulatory RNAs and target mRNA decay in prokaryotes. Biochim Biophys Acta, 2013. 1829(6-7): p. 742-7.

16. Waters, L.S. and G. Storz, Regulatory RNAs in bacteria. Cell, 2009. 136(4): p. 615-28.

17. Michaux, C., et al., Physiological roles of small RNA molecules. 
Microbiology, 2014. 160(Pt 6): p. 1007-19.

18. Han, R., et al., A Small Regulatory RNA Contributes to the Preferential Colonization of Escherichia coli O157:H7 in the Large Intestine in Response to a Low DNA Concentration. Front Microbiol, 2017. 8: p. 274.

19. Gimpel, M. and S. Brantl, Dual-function small regulatory RNAs in bacteria. Mol Microbiol, 2017. 103(3): p. 387-397.

20. Georg, J., et al., The small regulatory RNA SyR1/PsrR1 controls photosynthetic functions in cyanobacteria. Plant Cell, 2014. 26(9): p. 3661-79.

21. Sudo, N., et al., A novel small regulatory RNA enhances cell motility in enterohemorrhagic Escherichia coli. J Gen Appl Microbiol, 2014. 60(1): p. 44-50.

22. van der Meulen, S.B., A. de Jong, and J. Kok, Transcriptome landscape of Lactococcus lactis reveals many novel RNAs including a small regulatory RNA involved in carbon uptake and metabolism. RNA Biol, 2016. 13(3): p. 353-66.

23. Datsenko, K.A. and B.L. Wanner, One-step inactivation of chromosomal genes in Escherichia coli K-12 using PCR products. Proc Natl Acad Sci U S A, 2000. 97(12): p. 6640-5.

24. Li, J.H., et al., Trans-translation mediates tolerance to multiple antibiotics and stresses in Escherichia coli. Journal Of Antimicrobial Chemotherapy, 2013. 68(11): p. 2477-2481.

25. Li, Y. and Y. Zhang, PhoU is a persistence switch involved in persister formation and tolerance to multiple antibiotics and stresses in Escherichia coli. Antimicrob Agents Chemother, 2007. 51(6): p. 2092-9.

26. Wang, W.J., et al., Transposon Mutagenesis Identifies Novel Genes Associated with Staphylococcus aureus Persister Formation. Frontiers In Microbiology, 2015. 6.

27. Thomason, M.K., et al., A small RNA that regulates motility and biofilm formation in response to changes in nutrient availability in Escherichia coli. Molecular Microbiology, 2012. 84(1): p. 17-35.

28. Wu, N., et al., Ranking of persister genes in the same Escherichia coli genetic background demonstrates varying importance of individual persister genes in tolerance to different antibiotics. Frontiers In Microbiology, 2015. 6.

29. Keseler, I.M., et al., The EcoCyc database: reflecting new knowledge about Escherichia coli K-12. Nucleic Acids Research, 2017. 45(D1): p. D543-D550.

30. Urish, K.L., et al., Antibiotic-tolerant Staphylococcus aureus Biofilm Persists on Arthroplasty Materials. Clinical Orthopaedics And Related Research, 2016. 474(7): p. 1649-1656.

31. Attaran, B., T. Falsafi, and N. Ghorbanmehr, Effect of biofilm formation by clinical isolates of Helicobacter pylori on the efflux-mediated resistance to commonly used antibiotics. World Journal Of Gastroenterology, 2017. 23(7): p. 1163-1170.

32. Babra, C., et al., The persistence of biofilm-associated antibiotic resistance of Staphylococcus aureus isolated from clinical bovine mastitis cases in 
Australia. Folia Microbiologica, 2013. 58(6): p. 469-474.

33. Mah, T.F., et al., A genetic basis for Pseudomonas aeruginosa biofilm antibiotic resistance. Nature, 2003. 426(6964): p. 306-310.

34. Keren, I., et al., Specialized persister cells and the mechanism of multidrug tolerance in Escherichia coli. J Bacteriol, 2004. 186(24): p. 8172-80.

35. Lewis, K., Persister cells. Annu Rev Microbiol, 2010. 64: p. 357-72.

36. Modi, S.R., et al., Functional characterization of bacterial sRNAs using a network biology approach. Proceedings Of the National Academy Of Sciences Of the United States Of America, 2011. 108(37): p. 15522-15527.

37. van Nues, R.W., et al., Ribonucleoprotein particles of bacterial small non-coding RNA IsrA (IS61 or McaS) and its interaction with RNA polymerase core may link transcription to mRNA fate. Nucleic Acids Research, 2016. 44(6): p. 2577-2592.

38. Maisonneuve, E., M. Castro-Camargo, and K. Gerdes, (p)ppGpp controls bacterial persistence by stochastic induction of toxin-antitoxin activity. Cell, 2013. 154(5): p. 1140-1150.

39. Germain, E., et al., Stochastic induction of persister cells by HipA through (p)ppGpp-mediated activation of mRNA endonucleases. Proceedings Of the National Academy Of Sciences Of the United States Of America, 2015. 112(16): p. 5171-5176.

40. Delihas, N., Discovery and characterization of the first non-coding RNA that regulates gene expression, micF RNA: A historical perspective. World J Biol Chem, 2015. 6(4): p. 272-80.

41. Misra, R. and P.R. Reeves, Role of micF in the tolC-mediated regulation of OmpF, a major outer membrane protein of Escherichia coli K-12. J Bacteriol, 1987. 169(10): p. 4722-30.

42. Lee, H.J. and S. Gottesman, sRNA roles in regulating transcriptional regulators: Lrp and SoxS regulation by sRNAs. Nucleic Acids Research, 2016. 44(14): p. 6907-6923.

43. Coyer, J., et al., micF RNA in ompB mutants of Escherichia coli: different pathways regulate micF RNA levels in response to osmolarity and temperature change. J Bacteriol, 1990. 172(8): p. 4143-50.

44. Guo, M.S., et al., MicL, a new sigma(E)-dependent sRNA, combats envelope stress by repressing synthesis of Lpp, the major outer membrane lipoprotein. Genes \& Development, 2014. 28(14): p. 1620-1634.

45. Wright, P.R., et al., CopraRNA and IntaRNA: predicting small RNA targets, networks and interaction domains. Nucleic Acids Research, 2014. 42(W1): p. W119-W123.

46. Gogol, E.B., et al., Small RNAs endow a transcriptional activator with essential repressor functions for single-tier control of a global stress regulon. Proc Natl Acad Sci U S A, 2011. 108(31): p. 12875-80.

47. Groszewska, A., Z. Wroblewska, and M. Olejniczak, The structure of fadL mRNA and its interactions with RybB sRNA. Acta Biochimica Polonica, 2016. 63(4): p. 835-840. 
48. Serra, D.O., et al., The green tea polyphenol EGCG inhibits E-coli biofilm formation by impairing amyloid curli fibre assembly and downregulating the biofilm regulator CsgD via the sigma(E)-dependent sRNA RybB. Molecular Microbiology, 2016. 101(1): p. 136-151.

49. Klein, G. and S. Raina, Regulated Control of the Assembly and Diversity of LPS by Noncoding sRNAs. Biomed Research International, 2015.

50. Wassarman, K.M., et al., Identification of novel small RNAs using comparative genomics and microarrays. Genes Dev, 2001. 15(13): p. 1637-51.

51. Guillier, M. and S. Gottesman, Remodelling of the Escherichia coli outer membrane by two small regulatory RNAs. Molecular Microbiology, 2006. 59(1): p. 231-247.

52. Mika, F. and R. Hengge, Small RNAs in the control of RpoS, CsgD, and biofilm architecture of Escherichia coli. RNA Biol, 2014. 11(5): p. 494-507.

53. Tjaden, B., et al., Target prediction for small, noncoding RNAs in bacteria. Nucleic Acids Res, 2006. 34(9): p. 2791-802.

54. Bak, G., et al., Identification of novel sRNAs involved in biofilm formation, motility, and fimbriae formation in Escherichia coli. Sci Rep, 2015. 5: p. 15287.

55. Komasa, M., et al., A screening system for artificial small RNAs that inhibit the growth of Escherichia coli. Journal Of Biochemistry, 2011. 150(3): p. 289-294.

56. Wang, W., et al., Transposon Mutagenesis Identifies Novel Genes Associated with Staphylococcus aureus Persister Formation. Front Microbiol, 2015. 6.

57. Shi, W.L., et al., Pyrazinamide Inhibits Trans-Translation in Mycobacterium tuberculosis. Science, 2011. 333(6049): p. 1630-1632.

58. Harrison, J.J., R.J. Turner, and H. Ceri, Persister cells, the biofilm matrix and tolerance to metal cations in biofilm and planktonic Pseudomonas aeruginosa. Environmental Microbiology, 2005. 7(7): p. 981-994.

59. Yadav, M.K., et al., The Small Molecule DAM Inhibitor, Pyrimidinedione, Disrupts Streptococcus pneumoniae Biofilm Growth In Vitro. PLoS One, 2015. 10(10). 
bioRxiv preprint doi: https://doi.org/10,1101/310631; this version posted April 30,2018. The copyright holder for this preprint (which was

Fig. 1.

A

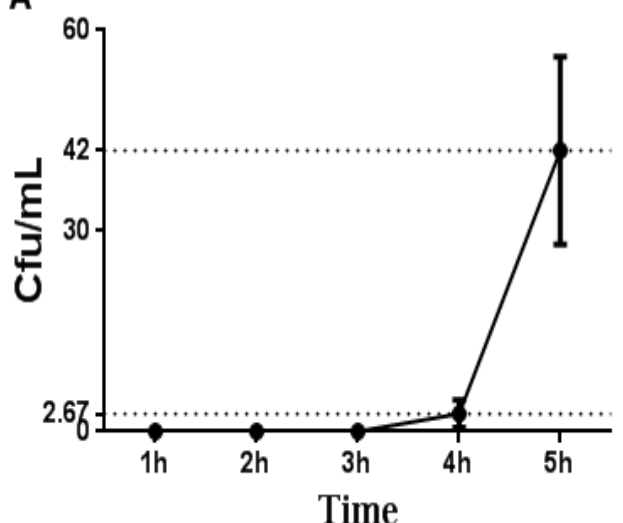

609

610

611

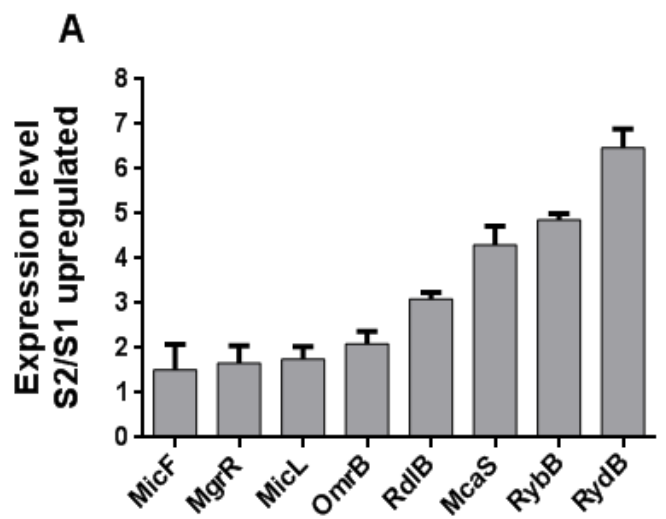

B

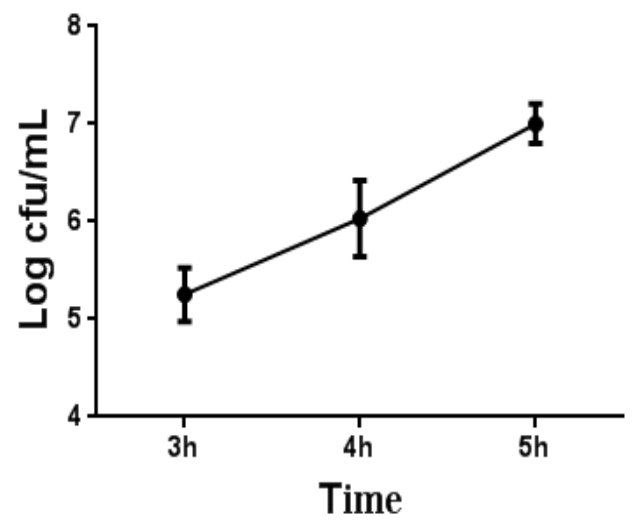

B

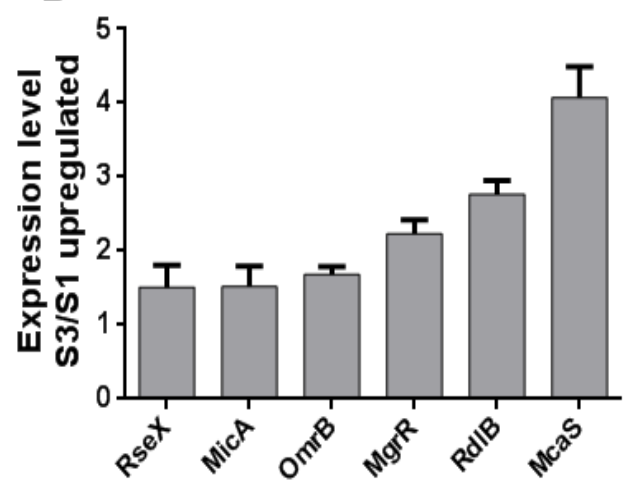

$612 \quad$ Fig. 3

613

614

A

B
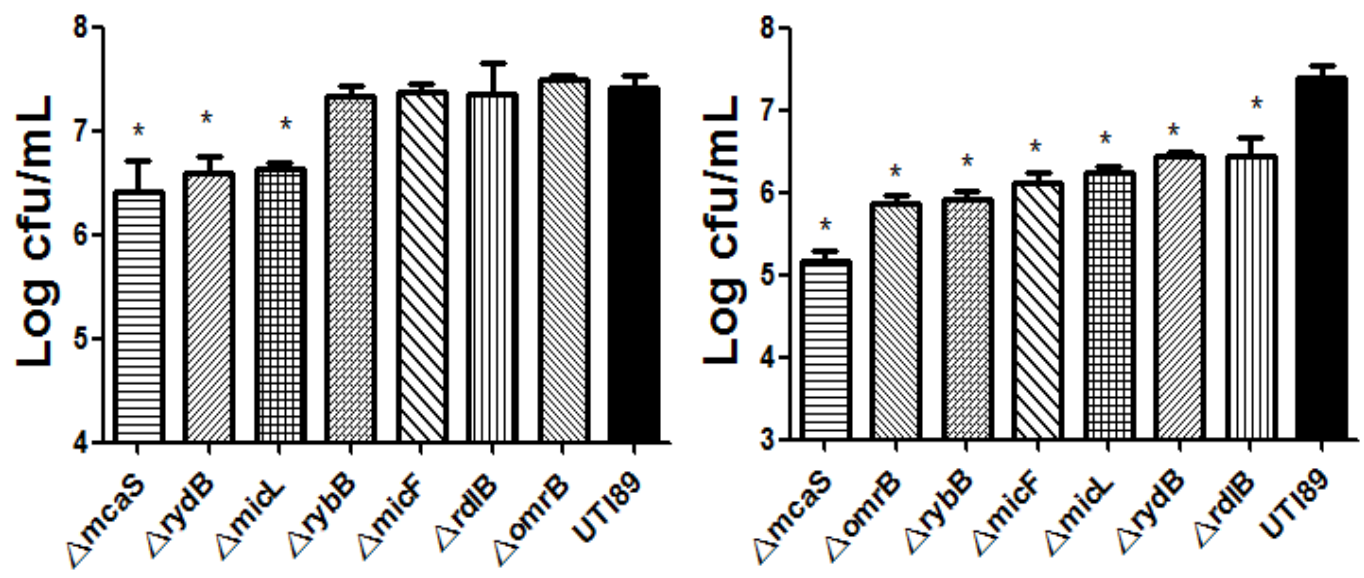

616

C

D 
617

618

619

620

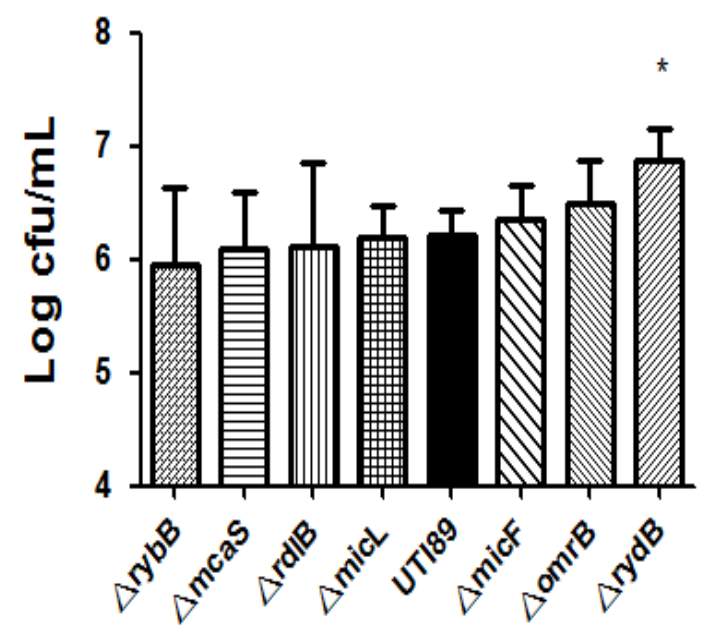

E

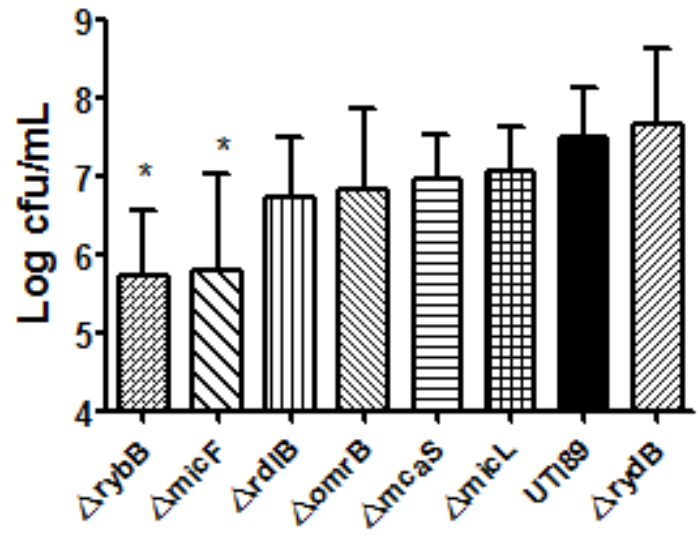

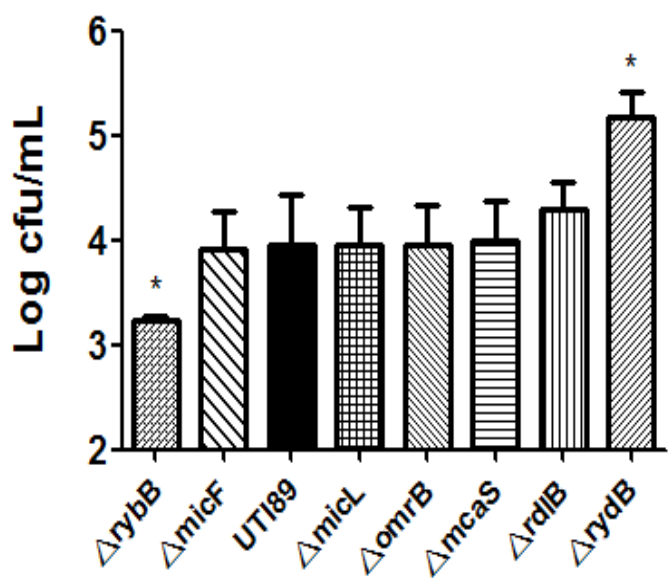

F

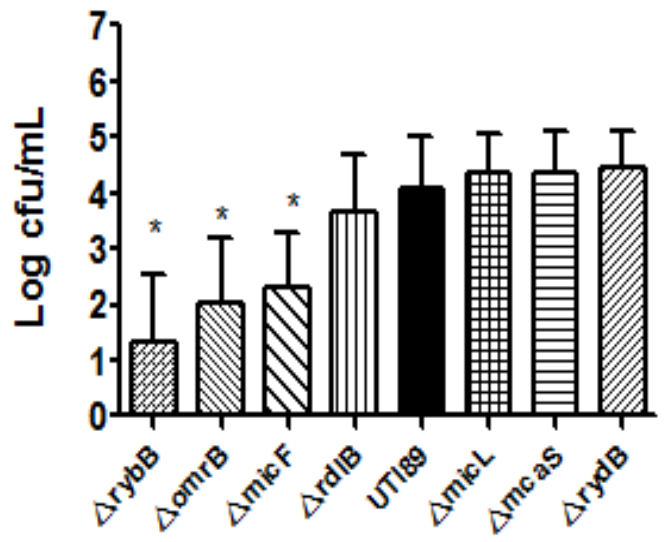

$\mathrm{H}$

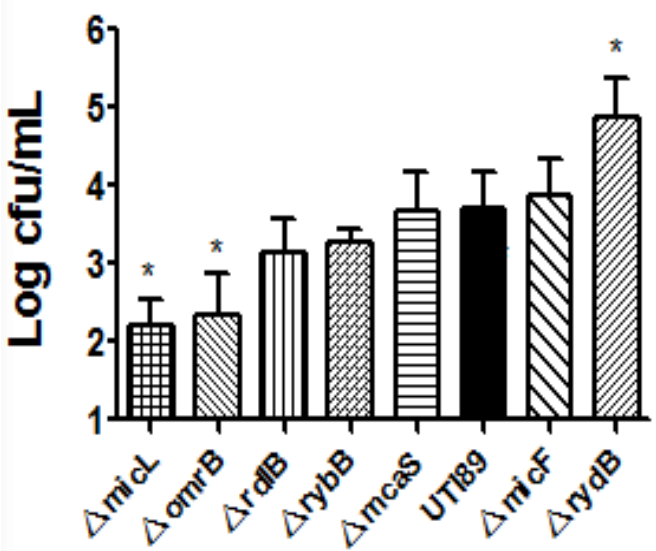

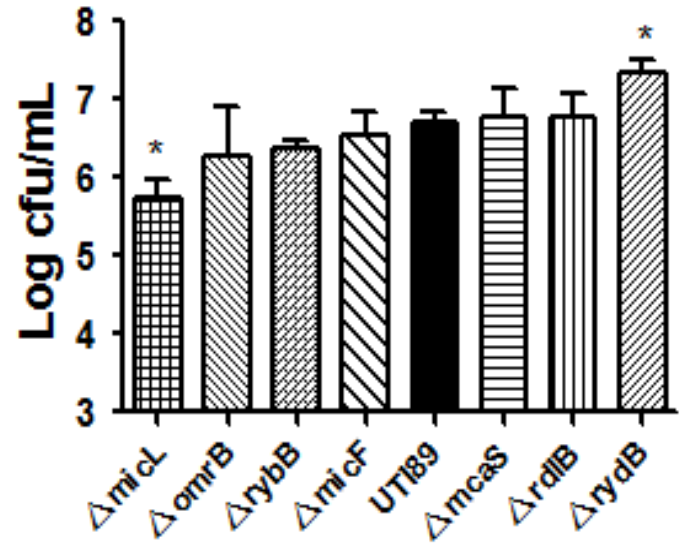

622 
bioRxiv preprint doi: https://doi.org/10.1101/310631; this version posted April 30,2018 . The copyright holder for this preprint (which was

not certified by peer review) is the author/funder, who has granted bioRxiv a license to display the preprint in perpetuity. It is made available under aCC-BY-NC-ND 4.0 International license.

630

631

632

A

633

634

C
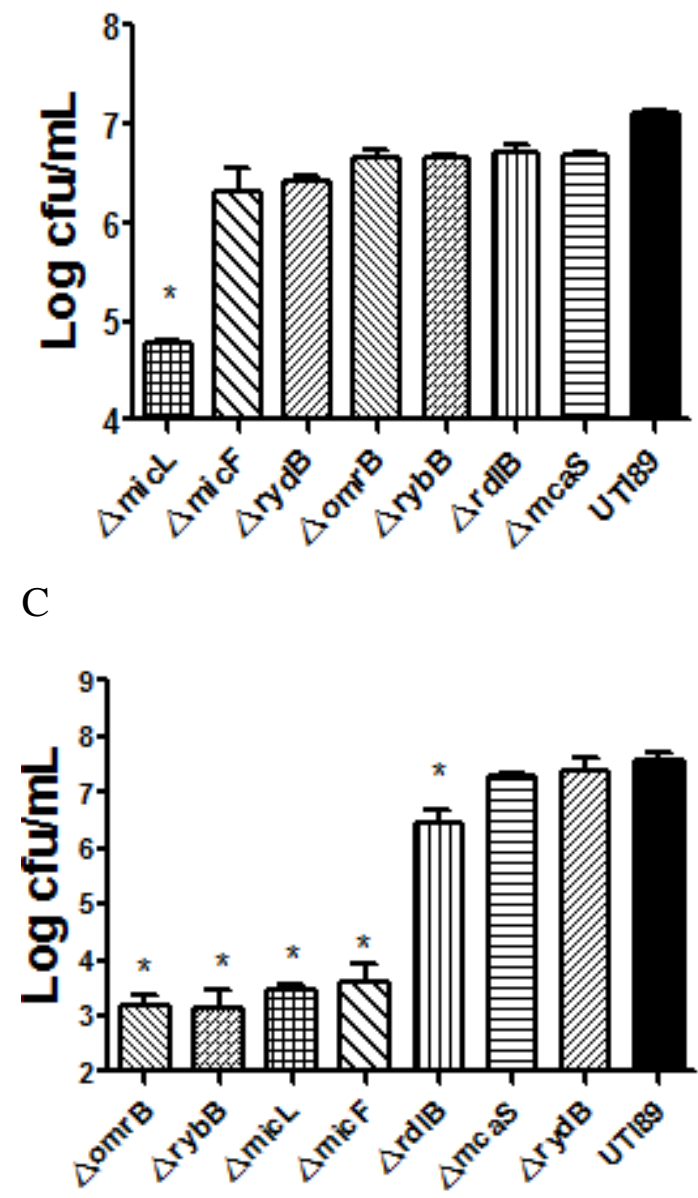

636

637

638

639

Fig 5.

640

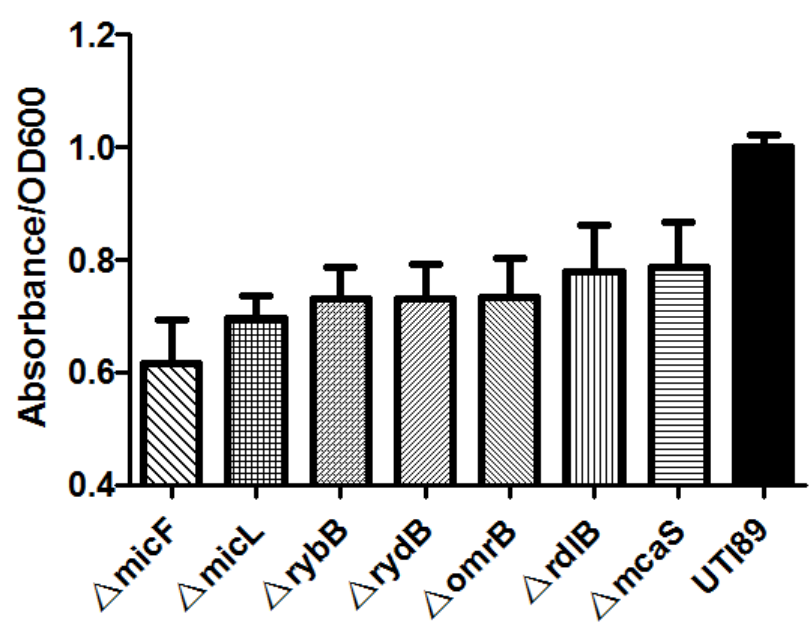

B

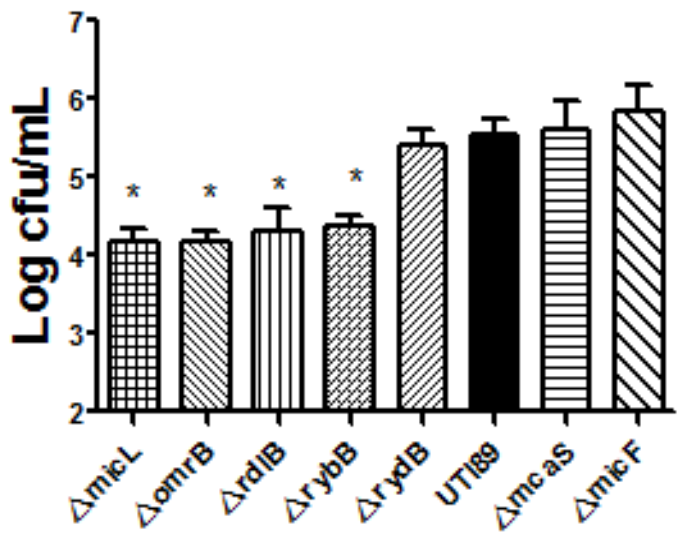

D

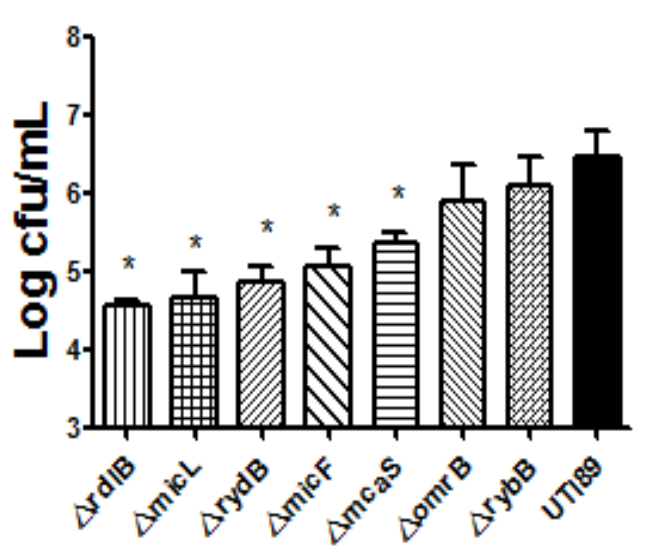

D 
bioRxiv preprint doi: https://doi.org/10.1101/310631; this version posted April 30, 2018. The copyright holder for this preprint (which was

not certified by peer review) is the author/funder, who has granted bioRxiv a license to display the preprint in perpetuity. It is made available under aCC-BY-NC-ND 4.0 International license.

Table S1. Primers used to generate gene-knockout mutants.

Gene Primer $\left(5^{\prime}-3^{\prime}\right)$

\begin{tabular}{|c|c|}
\hline$r y d B$ & $\begin{array}{l}\text { F: TCAGAAATAAGAAAACCCTTAAGTCTGTGCGACACAGGC } \\
\text { TTAAGGGTTTGTGTAGGCTGGAGCTGCTTC } \\
\text { R: AATAATACAAATCGCAGTTTGTGTTAAAACAGTGGGTTAGC } \\
\text { TTTATGAGATGGGAATTAGCCATGGTCC }\end{array}$ \\
\hline mcaS & $\begin{array}{l}\text { F: ATTCCCCAATCCCGGCGAGAATGTGGTTAT TTACAGAGCT } \\
\text { AAAAAATGAAGTGTAGGCTGGAGCTGCTTC } \\
\text { R: ACGGATGGGTAAAACCGTTATAACACTGTCACCGGTCACCAGG } \\
\text { ACCCCAG ATGGGAATTAGCCATGGTCC }\end{array}$ \\
\hline$r y b B$ & $\begin{array}{l}\text { F: GATTTTGAGGATGGTTGAGAGGATTGCTGGGTAGTAGATAA } \\
\text { ATTTCAGGCGTGTAGGCTGGAGCTGCTTC } \\
\text { R: TTTGCACAACCGCAGAACTTTTCCGCAGGGCATCAGTCTTA } \\
\text { ATTAGTGCCATGGGAATTAGCCATGGTCC }\end{array}$ \\
\hline$m i c F$ & $\begin{array}{l}\text { F: CAGCACTGAATGTCAAAACAAAACCTTCACTCGCAACTAG } \\
\text { AATAACTCCCGTGTAGGCTGGAGCTGCTTC } \\
\text { R: ATAGTTTTTCTGTGGTAGCACAGAATAATGAAAAGTGTGT } \\
\text { AAAGAAGGGTATGGAATTAGCCATGGTCC }\end{array}$ \\
\hline omrB & $\begin{array}{l}\text { F: TGCAACGAGGTGTGTAAATTGTCGGTTACTGTTACAGATT } \\
\text { GATGACCGGCGTGTAGGCTGGAGCTGCTTC } \\
\text { R: TTGCGATTGACTGCTGGTGGCGTTTGGCTTCAGGTTGCTAA } \\
\text { AGTGGTGATATGGGAATTAGCCATGGTCC }\end{array}$ \\
\hline
\end{tabular}


F: CCCGCTCAAC AGATCACGGC AATCGTTCGT TTTTTATACT GCTCAGGGATGTGTAGGCTGGAGCTGCTTC

micL R: GCGGCGGTTGCTGAAATGAAAGGAATCATTGAACGCCATCAG GCCAAATGATGGGAATTAGCCATGGTCC

F: AGCCGCCTTG TTGTAATGAC AACATTTTGC GGCTATTCTT

$r d l B$ GAATTGTTGA GTGTAGGCTGGAGCTGCTTC

R: GGCGCAATGTTGCGGGGGCTTTATCCCTGGTGGCATTGGTT GCTGGAAAG ATGGGAATTAGCCATGGTCC

Table S2. Primers used to verify gene knockout mutants.

\begin{tabular}{|c|c|}
\hline Gene & Primer $\left(5^{\prime}-3^{\prime}\right)$ \\
\hline$r y d B$ & $\begin{array}{l}\text { F: TTCAGAAATA AGAAAACCCT } \\
\text { R: AAATAATACAAATCGCAGTT }\end{array}$ \\
\hline mcas & $\begin{array}{l}\text { F: ATTCCCCAAT CCCGGCGAGA } \\
\text { R: ACGGATGGGTAAAACCGTTA }\end{array}$ \\
\hline$r y b B$ & $\begin{array}{l}\text { F: GATTTTGAGGATGGTTGAGA } \\
\text { R: TTTGCACAACCGCAGAACTT }\end{array}$ \\
\hline $\operatorname{micF}$ & $\begin{array}{l}\text { F: CAGCACTGAATGTCAAAACA } \\
\text { R: ATAGTTTTTCTGTGGTAGCA }\end{array}$ \\
\hline$o m r B$ & $\begin{array}{l}\text { F: TGCAACGAGGTGTGTAAATT } \\
\text { R: TTGCGATTGACTGCTGGTGG }\end{array}$ \\
\hline micL & $\begin{array}{l}\text { F: CCCGCTCAAC AGATCACGGC } \\
\text { R: GCGGCGGTTGCTGAAATGAA }\end{array}$ \\
\hline$r d l B$ & $\begin{array}{l}\text { F: AGCCGCCTTG TTGTAATGAC } \\
\text { R: GGCGCAATGTTGCGGGGGCT }\end{array}$ \\
\hline
\end{tabular}




\begin{tabular}{|c|c|}
\hline Gene & Primer $\left(5^{\prime}-3^{\prime}\right)$ \\
\hline \multirow{2}{*}{$r y d B$} & F: CATG CCATGG CTACCCCATCCGGCGCTT \\
\hline & R: CCCG GAATTC ATTATCCTTATCGCCCCTTCA \\
\hline \multirow{2}{*}{ mcaS } & F: CATG CCATGG TAAAAAAATAGAGCCTGTCGAC \\
\hline & R: CCCG GAATTC GCCGGATTTAAGACGAGGAT \\
\hline \multirow{2}{*}{$r y b B$} & F: CATG CCATGG GCCACTGCTTTTCTTTGATGT \\
\hline & R: CCCG GAATTC ACAAAAAACCCATCAACCTTGA \\
\hline \multirow{2}{*}{$\operatorname{micF}$} & F: CATG CCATGG GCTATCATCATTAACTTTATTTATT \\
\hline & R: CCCG GAATTC AAAAAAAACCGGATGCGAGGC \\
\hline \multirow{2}{*}{$o m r B$} & F: CATG CCATGG CCCAGAGGTATTGATAGGTG \\
\hline & R: CCCG GAATTC AAAAAAAACCTGCGCATCTGC \\
\hline \multirow{2}{*}{ micL } & F: CATG CCATGG ATTTTTACCGTTGCATCATGTC \\
\hline & R: CCCG GAATTC AAAAAAAGGCCCCTGTTGAAAT \\
\hline \multirow{2}{*}{$r d l B$} & F: CATG CCATGG TGGTTCAAGATTAGCCCCCG \\
\hline & R: CCCG GAATTC AGAAAACCCCCGCACGTTGA \\
\hline
\end{tabular}

